\title{
Spiritual Practices for Emotional Healing: Implications for Training Trauma Therapists
}

\author{
L N Suman* \\ Department of Clinical Psychology, National Institute of Mental Health and Neurosciences (NIMHANS), India
}

Submission: November 18, 2015; Published: December 02, 2015

*Corresponding author: L N Suman, Professor, Department of Clinical Psychology, Consultant, Trauma Recovery Clinic, National Institute of Mental Health and Neurosciences (NIMHANS), Bangalore 560 029, India, Email: elenes@nimhans.ac.in

\begin{abstract}
Mental health and well-being are important contributors to quality of life, productivity and life satisfaction. Spirituality is an important aspect of quality of life and hence, understanding spirituality, assessing spirituality and incorporating spirituality in psychotherapy are important issues for clinical psychologists in order to provide holistic and appropriate care. Professional ethics codes recognize the need to respect the beliefs and values associated with religion and spirituality in the course of psychotherapy. Spiritually oriented psychotherapeutic interventions have been considered to be especially indicated for individuals experiencing psychological trauma. Although the role of spirituality has been recognized in resilience and recovery, very little professional training is available for therapists to learn how to address religious-spiritual matters in therapy.Therapy training manuals and trained mentors are required to enable effective application of spiritually oriented psychotherapeutic interventions when they are indicated.
\end{abstract}

Keywords: Spirituality; Emotional healing; Psychotherapy; Therapy training

\section{Opinion}

The World Health Organization [1] has defined health as a state of complete physical, social and mental well-being, and not merely the absence of disease or infirmity. The definition indicates that quality of life is an important determinant of wellbeing. According to the [2], quality of life refers to a subjective evaluation by an individual of their position in life which is embedded in acultural, social and environmental context. It identified six broad domains whichdescribe core aspects of quality of life cross-culturally: a physical domain (e.g. energy, fatigue), a psychological domain (e.g. positive feelings), level of independence (e.g. mobility), social relationships (e.g. practical social support), environment (e.g. accessibilityof health care) and personal beliefs/spirituality (e.g. meaning in life). These domains are assessed by the WHO Quality of Life scale (WHOQOL) [3].

In 1984, the thirty seventh World Health Assembly took the historic decision to adopt a resolution which made the "spiritual dimension" a part of WHO Member States' strategies for health [4]. In 1997, the special group of the WHO Executive Board for the review of the Constitution proposed that the preamble be modified to read as"Health is a dynamic state of complete physical, mental, spiritual and social well-being and not merely the absence of disease or infirmity" [5]. In order to assess the spiritual dimension of quality of life, the WHO [6] developed the WHOQOL-SRPB to examine quality of life aspects related to spirituality, religiousness and personal beliefs.It assesses eight dimensions: spiritual connection, meaning and purpose in life,experiences of awe and wonder, wholeness and integration,spiritual strength,inner peace,hope and optimism, and faith.The WHOQOL-SRPB examines the relationship between quality of life and spirituality, religiosity and personal beliefs [7].

Such a perspective of health and wellness gives spirituality a dominant position in terms of utilizing it for emotional wellbeing as well as for maintaining equanimity in the face of life's challenges. This has implications for both resilience in the face of psychological trauma as well as for recovery among those who struggle to overcome its impact. Verghese [8] noted that spirituality produces in man qualities such as love, honesty, patience, tolerance, compassion, a sense of detachment, faith, and hope. These ennobling qualities may provide a person with inner strength to overcome difficult life circumstances and enable emotional healing. If spirituality has such healing qualities, its presence in individuals seeking psychological help needs to be 
recognized and utilized. For this dimension to be integrated in counselling and psychotherapy, the spirituality of the counsellor or therapist may play a role. Further, the counsellor or therapist must be open to the idea of incorporating spiritual issues and techniques during the course of intervention.

The Ethics Code of the American Psychological Association (APA, 2002) states that psychologists should consider religion and religious issues as they do any other kind of diversity. The Code thus requires some degree of sensitivity and training on religious-diversity related issues.Professional ethics codes now recognize the need to respect the beliefs and values associated with religion and spirituality and to avoid pathologizing those who seek religious and spiritual growth, development, and involvement. Since religion and spirituality play an important role in the lives of most people, it would be irresponsible to ignore such a critical aspect of peoples' lives in the course of psychotherapy. Psychologists and other mental health professionals need to be clearly aware of their areas of competence and obtain adequate training and supervision if they plan to integrate spirituality and religion into their professional psychological work [9].

Knox et al. [10] recommended training therapists to address religious-spiritual content that emerges in the process of counselling and psychotherapy. They opined that there is a need to educate therapists to explore the impact of clients' and therapists' religious-spiritual orientation on therapy content and process. This would be on the lines of incorporating training related to other multicultural factors in therapy such as age, gender and sexual orientation of the patients which most training programs follow. They noted that the lack of training in religion and spirituality in psychotherapy may also serve as animpediment to the development of culturally competent counselors. This may prove troublesome especially when clients wish to address religious-spiritual matters in therapy. Adequate training in this domain will prevent therapists from believing that they do not have expertise in religious-spiritual matters and that such patients ought to be referred to other professionals such as priests and the clergy.

In a review of literature on the roles of spirituality and religion in mental health and illness and the place of religion in psychotherapy, Bienenfeld and Yager [11] found that a Medline search for the terms religion or spirituality,andsupervision ortraining as well aspsychotherapy, for the years 1990 through 2006, resulted in only 62 citations. Of them, just five actually described or reported elements of religion and spirituality in psychotherapy supervision, and only two were in the context of training. They recommended the development of training curricula that foster an understanding of the terms religion and spirituality; using a framework for understanding spiritual development; making distinctions between religious beliefs and behaviors and psychopathological ones; enhancing selfawareness about religious and spiritual issues. Utsch [12] noted that when literature on religion and health is reviewed, the potential negative effects of religion are rarely discussed. As a result, the harmful effects of spirituality are often neglected, leading to incomplete and inadequate understanding of the domain. Hence, research is important for appropriate training content as well as techniques.

According to Post and Wade [13], the question for clinicians is no longer whether to address the sacred in psychotherapy with religious and spiritual clients, but when and how to address the sacred. In a review of research in this area, they cited studies that showed that only $13 \%$ of APA-accredited clinical psychology program offers a specific course in religion/spirituality and psychology; $17 \%$ covered the topic systematically and $16 \%$ of the training programs did not address the topic at all. Further, despite the need for specific training, therapists were unlikely to receive encouragement to explore their own religious/spiritual beliefs and biases. They noted that lack of training may explain why many therapists lack confidence in their ability to work effectively with religious/spiritual clients. They recommended that therapists should seek out mentors and resources to become informed on this subject. As explained by Shapiro, Lee and Gross [14], the integration of spirituality and psychology through theory, practice, research and training is the domain of transpersonal psychology. Using scientific methods to make transpersonal psychology a scientific approach or discipline is important.

Spiritually oriented psychotherapeutic interventions have been considered to be especially indicated for individuals experiencing psychological trauma. Such interventions have been used for individuals with diverse clinical problems such as HIV/AIDS, eating and addictive disorders, social anxiety and depression, medical illnesses, and relational experiences such as sexual abuse and divorce.Thehealing approachesemploy various spiritually-oriented interventions including prayer, meditation, spiritual visualization, reframing, support, journaling, scripture reading, purification rituals, forgiveness activities and encouraging spiritual virtues such as sharing, empathy, gratitude and appreciation.Pargament, Koenig and Perez [15] noted that religion serves a variety of purposes inday-to-day living and in crisis. Five key functions of religion that enable coping with a negative life event were: providing meaning to life; providing avenues to achieve a sense of mastery and control; deriving comfort; facilitating intimacy with others as well as with a higher power; assisting people in making major life transformations. These functions of religion may aid individuals to come to terms with not only single life-changing traumatic events but also help individuals cope with complex trauma.

Peres et al. [16] opined that since religiousness and spirituality were based on a personal quest for understanding issues related to life and its meaning, they would enable patients with post-traumatic stress disorder to synthesize the traumatic experience in a comprehensive and healing narrative. They also suggested that the study of the role of spirituality in fostering 
resilience in trauma survivors may advance understanding of human adaptation to trauma.In a review of perspectives on religion and spirituality in recovery from serious mental illness and substance abuse, Fallot [17] concluded that mental health services need to become 'spiritually-informed' to address issues related to psychological trauma. Since trauma informed services are related to a wide range of human problems, the role of spirituality in recovery could be examined. This would require mental health professionals to be not only responsive to the spiritual dimension but also develop 'spiritually-specific' interventions.

In multi-religious countries like India, the therapist has to be culturally informed about the diverse belief systems pertaining to religion, spirituality, sacred practices, explanatory models of health and illness based on attributions to divine and evil forces in the supernatural world, and other personal beliefs such as rebirth and karma. Training in multiculturalism will enable the therapist to understand the patients' perspective and respect their viewpoint. Such training is important for promoting congruence between the therapist and the patient and strengthening the therapeutic alliance. The therapist must also recognize that some patients may not be spiritually inclined and must desist from using spiritual approaches in such cases. Spiritual techniques may also have to be tailor-made to suit the unique belief system of the patient and his family. In all cases, the secular fabric of psychotherapy needs to be maintained by ensuring that the spiritual dimension focuses on promoting recovery and does not demean otherreligions or spiritual practices.Further, spiritually oriented interventions need to be examined for effectiveness in cases of psychological trauma.

\section{Conclusion}

The spiritual dimension of health and well-being needs to be recognized by mental health professionals. Faith based approaches have been found to aid recovery in patients with mental illness and substance abuse. They have also been found to be effective in addressing problems related to trauma experiences. Psychological trauma experiences are ubiquitous in today's world and significantly impact people of all ages. This indicates a need for more efforts at research and training related to religious and spiritual interventions. Spirituality may also act as a protective factor against trauma experiences and thereby contribute to resilience. The secular fabric of psychotherapy must be adhered to in practice using faith based interventions.

\section{References}

1. World Health Organization (WHO) (1948) Preamble to the Constitution of the World Health Organization as adopted by the International Health Conference, New York, 19-22 June, 1946; signed on 22 July 1946 by the representatives of 61 States (Official Records of the World Health Organization, no. 2, p. 100) and entered into force on 7 April 1948. WHO, Geneva, Switzerland.

2. World Health Organization (WHO) (1994) Quality of Life Assessment. The WHOQOL Group. WHO Publication, Geneva, Switzerland.

3. The WHOQOL Group (1998) The World Health Organization Quality of Life Assessment (WHOQOL): Development and general psychometric properties. Soc Sci Med 46(12): 1569-1585.

4. World Health Organization (WHO) (1985) Handbook of resolutions and decisions. Vol. II: 5-6. Geneva, WHO Publication, Geneva, Switzerland.

5. World Health Organization (WHO) (1997) Review of the constitution. 10, 1/7:2. WHO Publication, Geneva, Switzerland.

6. The WHOQOL SRPB Group (2006) A cross-cultural study of spirituality, religion, and personal beliefs as components of quality of life. Soc Sci Med 62(6): 1486-1497.

7. Fleck MP, Skevington S (2007) Explaining the meaning of the WHOQOL-SRPB. Rev psiquiatr clín 34(Suppl 1): 67-69.

8. Verghese A (2008) Spirituality and mental health. Indian J Psychiatry 50(4): 233-237.

9. Plante TG (2007) Integrating spirituality and psychotherapy: Ethical issues and principles to consider. J Clin Psychol 63(9): 891-902.

10. Knox S, Catlin L, Casper M, Schlosser LZ (2005) Addressing religion and spirituality in psychotherapy: Clients' perspectives. Psychother Res 15(3): 287-303.

11. Bienenfeld D, Yager J (2007) Issues of spirituality and religion in psychotherapy supervision. Isr J Psychiatry Relat Sci 44(3): 178-186.

12. Utsch M (2007) The challenge of psychotherapy for religion and spirituality. Psyche \& Geloof 18: 86-95.

13. Post BC, Wade NG (2009) Religion and spirituality in psychotherapy: A practice friendly review of research. J Clin Psychol 65(2): 131-146.

14. Shapiro SI, Lee GW, Gross PL (2002) The essence of transpersonal psychology: Contemporary views. The International Journal of Transpersonal Studies 21: 19-32.

15. Pargament KI, Koenig HG, Perez LM (2000) The many methods of religious coping: Development and initial validation of the RCOPE. J Clin Psychol 56(4): 519-543.

16. Peres JFP, Moreira-Almeida A, Nasello AG, Koenig HG (2007) Spirituality and resilience in trauma victims. J Relig Health 46: 343350.

17. Fallot RD (2007) Spirituality and religion in recovery: Some current issues. Psychiatr Rehabil J 30(4): 261-270. 